\title{
O Iluminismo português e a literatura instrutiva: uma
} visão holística ${ }^{1}$

\author{
Júnior César Pereira ${ }^{2}$
}

Resumo: O trabalho em foco tem como objetivo apresentar os principais aspectos da literatura instrutiva portuguesa no setecentos. O século XVIII foi decisivo para o rumo de Portugal e seus domínios, uma vez que nessa época o Reino lusitano entrou em contato com as novas ideias oriundas do movimento iluminista por meio de vários homens de letras e da atuação política de Sebastião José de Carvalho e Melo, o poderoso Marquês de Pombal, ministro de D. José I. Nesse seguimento, traçamos nossa empreitada: visualizar a Ilustração lusitana por meio de sua produção intelectual. Como esses ilustrados justificaram a relação entre fé e razão? Por que os jesuítas foram culpados pelo atraso cultural do Reino? Quem eram esses pensadores? Como se deram as Reformas Pombalinas na educação? Estas e outras perguntas norteiam nosso trabalho.

Palavras-chave: Iluminismo português, literatura instrutiva, homens de letras.

Abstract: The main objective of this work is to present the main aspects of the Portuguese instructional literature in the Seventeen hundreds. The eighteenth century was decisive for the direction of Portugal and its dominions, since at that time the Lusitanian Kingdom came into contact with the new ideas originating from the Enlightenment movement through several intellectuals (Estrangeirados) and the political action of Sebastião José de Carvalho e Melo, the powerful Marquis of Pombal, minister of D. José I. In this sequence we draw our work: to visualize the Lusitanian Illustration through its intellectual production. How did intellectuals justify the relationship between faith and reason? Why were the Jesuits guilty of the cultural backwardness of the Kingdom? Who were these thinkers? How happened the Pombaline Reforms in education? These and other questions guide our work.

${ }^{1} \mathrm{O}$ presente trabalho corresponde ao segundo capítulo do trabalho de conclusão de curso intitulado "Manuel Inácio da Silva Alvarenga: trajetória de um homem de letras (1749-1814)".

${ }^{2}$ Mestrando em História na Universidade Estadual de Londrina e bolsista Capes sob orientação da Profa. Dra. Maria Renata da Cruz Duran.

Revista Vernáculo n. ${ }^{\circ} 42$ - segundo semestre /2018

ISSN 2317-4021 
Key-words: Portuguese Enlightenment, Instructional Literature, Intellectuals.

\section{Introdução: As Luzes em Portugal}

As atividades intelectuais e acadêmicas promovidas por D. Rafael Bluteau e pelo 4. Conde da Ericeira, D. Francisco Xavier de Meneses, assinalaram em Portugal um movimento inicial de convergência com os ventos renovadores da cultura iluminista que grassava em algumas partes da Europa. ${ }^{3}$ Sob a égide de D. João V vemos diversos marcos importantes para a participação do Reino Lusitano nesse novo cenário, como a instituição da Aula de Física Experimental no Palácio das Necessidades, e ainda as aulas de Filosofia proferidas pelo P. João Baptista na Congregação do Oratório. A década de 1740 vê a publicação do Verdadeiro método de estudar, de Luís Antônio Verney, e da Lógica racional, geométrica e analítica de Manuel Azevedo Fortes, obras basilares da ilustração portuguesa. ${ }^{4}$

Importante nome da política portuguesa no reinado de D. José I, Sebastião José de Carvalho e Melo, o Marquês de Pombal, proporcionou em grande medida as condições para o estabelecimento do iluminismo em Portugal. Sob seu governo é publicada a Dedução Cronológica e Analítica (1768) que precede os dois documentos mais característicos no que tange às reformas empreendidas no âmbito

3 BIRON, Berty. Considerações acerca do iluminismo luso-brasileiro. RCL, Convergência Lusíada, n. 32, jul. / dez. 2014.

${ }^{4}$ TUNA, Gustavo Henrique. Silva Alvarenga: representante das luzes na América portuguesa. Faculdade de filosofia, letras e ciências humanas, Universidade de São Paulo, São Paulo: Tese de Doutorado em História social, 2009. pp.14-25.

Revista Vernáculo n. ${ }^{\circ} 42$ - segundo semestre /2018 
educacional: o Compêndio histórico do estado da Universidade de Coimbra (1771) e os novos Estatutos da Universidade de Coimbra (1772)..$^{5}$

Nesse quadro nota-se uma contraposição deveras elucidativa: de um lado as trevas, representadas pelos inacianos; de outro, as luzes redentoras tendo o Estado pombalino como baluarte. ${ }^{6}$ A Companhia de Jesus foi eleita como a principal responsável pelo atraso e decadência intelectual do Reino; nesse sentido urgia a expulsão destes homens, responsáveis pela educação até aquele momento. A repressão aos jesuítas não deve ser compreendida como a negação da religião em detrimento das luzes. O iluminismo em Portugal não foi avesso ao catolicismo, pelo contrário, buscou atualizar a tradição de pensamento católico aos novos paradigmas oriundos da Ilustração. Antônio Ribeiro dos Santos, D. Frei Manuel do Cenáculo Villas Boas e Teodoro de Almeida são exemplos de pensadores católicos portugueses que se alinharam com os parâmetros iluministas, configurando uma corrente de pensamento apologética. Em suma, o que houve foi o intuito de secularizar a sociedade, delimitar as esferas de ação das instituições sociais e espiritualizar a igreja. ${ }^{7}$

${ }^{5}$ CARDOSO, Tereza Maria Rolo Fachada Levy. As luzes da educação: fundamentos, raízes históricas e prática das aulas régias no Rio de Janeiro. 1759-1834. Bragança Paulista: Editora da Universidade São Francisco, 2002, pp. 141-143.

6 CARVAlHO, Flávio Rey de. Um Iluminismo português? A Reforma da Universidade de Coimbra de 1772. Universidade de Brasília: Dissertação de Mestrado em História: 2007. p. 35.

${ }^{7}$ SANTOS, Cândido dos. Matrizes do Iluminismo católico da época pombalina. Faculdade de Letras da Universidade do Porto, 2004, p. 949-956.

Revista Vernáculo n. ${ }^{\circ} 42$ - segundo semestre $/ 2018$ 
Nesse seguimento, os pensadores portugueses dessa conjuntura objetivaram recuperar o ideal humanista no que tange ao ensino das línguas clássicas, como o latim, grego e hebraico, além da retórica, que a partir do alvará de 28 de junho de 1759 revestiu-se de singular importância na educação lusitana por conta da eficácia persuasiva do discurso no âmbito da comunicação, elemento crucial previsto pelo novo ideal pedagógico, assim como a filosofia natural, matéria fundamental que ganhou espaço em Coimbra com a reforma de 1772. Além dessas áreas do conhecimento, destacam-se ainda a Filosofia Racional, em concordância com os princípios lockeanos, a Filosofia Moral, iluminadora da pura razão, e ainda a teologia moral alinhada ao âmbito da reflexão jurisprudencial. $^{8}$

A noção de método é de fulcral importância para compreendermos o pedagogismo dessa época. Tal termo traduzia-se pela eficaz ordenação do pensamento no intuito de auferir a verdade, e comunicá-la a posteriori. Tal conceito foi refletido no âmbito da lógica, que por meio dos pensadores que se dedicaram a tal matéria assumiu um caráter psicologista, seguindo na esteira de Port-Royal e atacando o sistema cartesiano que defendia a existência de ideias inatas. ${ }^{9}$

No âmbito dos estudos jurídicos os preceitos jusnaturalistas de cariz não escolástico já circulavam em Portugal antes das reformas pombalinas, no entanto foi apenas com estas que a matéria foi reformulada em grande medida. Desse modo, adotou-se o discurso histórico e jurisdicista por um lado, e por outro, um discurso teológico e

8 TEIXEIRA, Ivan. Mecenato pombalino e a poesia neoclássica. São Paulo: Edusp, 1999, p. 188-189.

9 CARVAlHO JÚNIOR, Eduardo Teixeira de. O método em Verney e o Iluminismo em Portugal. Universidade Federal do Paraná, Curitiba: Tese de Doutorado em História, 2015, p. 114-120.

Revista Vernáculo n. ${ }^{\circ} 42$ - segundo semestre $/ 2018$

ISSN 2317-4021 
canônico em vistas a defender a autonomia do Estado perante a igreja no plano secular. Escrita sob o aval de Pombal, a Dedução Cronológica e Analítica desempenhou o papel de fundamentadora da soberania do Estado absoluto, preconizando a história do direito pátrio. ${ }^{10}$

Tais aspectos dão conta de nos proporcionar uma visão holística a respeito da peculiar ilustração lusitana. Na sequência buscaremos olhar mais de perto a Reforma da Universidade de Coimbra, tendo em vista que tal empresa foi considerada pela historiografia o pináculo das Luzes em Portugal; também procuraremos localizar alguns dos aspectos referidos anteriormente na trajetória dos vultos do Império luso, destacando a conformação pedagógica de suas produções, e pondo em tela os representantes do Arcadismo lusobrasileiro. Sendo assim, comecemos pela cidade do Mondego.

\section{Atraso cultural ou trama política?}

A Reforma da Universidade de Coimbra realizada em 1772 é considerada o ponto nevrálgico do processo de assimilação das ideias iluministas em Portugal, conseguindo, por sua vez, amplo alcance no Reino, aonde as ideias circunscreviam-se em agremiações de eruditos e setores da elite até então. Foram reformados os estudos de Teologia, Medicina, Leis e Cânones, e criaram-se os cursos de Filosofia e Matemática. As faculdades de Leis e de Filosofia foram as que

10 COSTA, Mário Júlio de Almeida; MARCOS, Rui de Figueiredo. Reforma Pombalina dos estudos jurídicos. O Marquês de Pombal e a Universidade, Coimbra, imprensa da Universidade, $2^{\mathrm{a}}$ ed, maio 2014. p. 97-125.

Revista Vernáculo n. ${ }^{\circ} 42$ - segundo semestre /2018 
notadamente incorporaram de maneira institucional os ideários ilustrados. Precedidos pela Relação Geral do Estado da Universidade e pelo Compêndio Histórico da Universidade (1771), os Estatutos materializaram as ideias ilustradas em Portugal, os quais redefiniram sob a nova ótica do pensamento científico os pré-requisitos para a admissão de estudantes, os métodos, os conceitos fundamentais, as disciplinas a serem ministradas, os autores e suas respectivas obras etc. Tal documento foi dividido em três volumes: um dedicado à faculdade de teologia, outro para o curso jurídico, e ainda um para as ciências naturais e filosóficas. ${ }^{11}$

Como demarcado acima, o clima intelectual renovador que fezse notar em Portugal no século XVIII esteve imbricado com a política vigente. Nesse quadro, a modernização de Portugal inseria-se num programa de interesses mais amplos por parte da Coroa. O poder régio tencionava recrudescer-se e granjear o revigoramento da economia do império. Para mais, tinha em vista realizar a implementação de nova lógica jurídica, racionalizada, não-pluralista, e sobrepujar a crise dos rendimentos, o que requeria um maior fluxo dos produtos exportados da colônia, por meio do incentivo da pesquisa. ${ }^{12}$

Eis a trama política e punha-se em tela os pressupostos da reforma da faculdade de leis e da criação da faculdade de filosofia: realizar o atendimento dos desígnios da monarquia lusa de criar um quadro científico, intelectual e administrativo, composto por

${ }^{11}$ SILVEIRA, Flávio Rey de. Op. cit., p. 52.

${ }^{12}$ Ibidem, p. 114-115.

Revista Vernáculo n. ${ }^{\circ} 42$ - segundo semestre /2018 
funcionários régios para atenderem seus interesses jurídico-econômicos. E ficou clara, nestes, a assimilação dos princípios metodológicos e epistemológicos dos iluministas. Pombal, a seu tempo, cercou-se das mentes mais reluzentes do Portugal setecentista. ${ }^{13}$

Um dos pontos nodais do movimento que estamos analisando é a vituperação da Companhia de Jesus. Com base nos novos influxos da filosofia ilustrada, os pensadores portugueses atacaram com afinco o modo educacional dos inacianos. Entrementes, de que maneira o edifício educacional português estava conformado em relação aos demais pela Europa? Até que ponto este se encontrava em decadência? Em que medida a relação entre trevas e ensino jesuíta fora fabricada em uma esfera política?

A maioria das universidades europeias do período, em termos estatutários, pautava-se pelo modelo escolástico de instrução, um saber caracterizado por perfil literário, especulativo e metafísico, fundamentando-se na dogmática dos padres da igreja, em contradição com a práxis epistemológica científico-experimental moderna. Do século XII ao XVII optou-se pelo método de leitura e análise de textos, e a disputa em torno das questões suscitadas por tal exercício (lectio e disputatio). ${ }^{14}$

Com o Concílio de Trento (1545-1563), houve a afirmação do método escolástico como arquétipo epistemológico do pensamento católico. Nesse cenário a Ratio Studiorum é publicada em 1599, com

${ }^{13}$ Ibidem.

${ }^{14}$ Ibidem, p. 29.

Revista Vernáculo n. ${ }^{\circ} 42$ - segundo semestre /2018

ISSN 2317-4021 
base nos fundamentos de Aquino, em comunhão com problemáticas emergidas das transformações que atingiam o imaginário europeu à época. Destarte, a atualização da cosmologia católica em virtude dos acontecimentos provados pela Reforma ganhou grande espaço nas universidades europeias. ${ }^{15}$

Os pensadores do século XVIII teceram severas críticas às conjecturas metafísicas do racionalismo matemático seiscentista e do escolasticismo. A gnosiologia ilustrada era pautada pelo método indutivo, empírico e experimental. As universidades do início do século XVIII estavam alheias aos estudos de filosofia natural. Tais saberes eram desenvolvidos fora do âmbito universitário. Este século ficou conhecido como o século das academias, locais onde tais conhecimentos eram cultivados, devido ao conservadorismo das universidades. ${ }^{16}$

Na primeira metade do XVIII havia duas universidades em Portugal que em termos estatutários não diferiam das demais universidades europeias. Em Coimbra o cenário acadêmico compunhase de um curso jurídico, teológico e médico, onde o objetivo era a formação de um contingente de profissionais. A Universidade de Évora era composta pelo curso de Humanidades, abrangendo as Artes, e a Teologia voltada para os casos de consciência. Essa instituição estava voltada para a conformação de um quadro de religiosos. ${ }^{17}$

\footnotetext{
${ }^{15}$ Ibidem, p. 30.

${ }^{16}$ Ibidem, p. 31.

${ }^{17}$ Ibidem, p. 32.
} 
Na esteira de Fernando Taveira da Fonseca, Flávio Rey de Silveira defende a ideia de que é preciso rever a ideia de decadência da Universidade de Coimbra entre 1555 e 1772, veiculada pela historiografia; para isso, basta notar que, em relação a diversas universidades europeias, o número de matriculados era enorme.

\begin{abstract}
Para a maioria dos portugueses que viveram no século XVII, e em parte do XVIII, a situação intelectual de Portugal não era de declínio, inexistindo, grosso modo, a noção de inferioridade cultural em relação ao estrangeiro. Nessa época, os imperativos doutrinários religiosos decorrentes da opção lusa pela manutenção do catolicismo, conforme as diretrizes estabelecidas no Concílio de Trento geraram certo preconceito ao conhecimento vindo de fora do país. ${ }^{18}$
\end{abstract}

Já vimos que no período joanino (1707-1750) houve um considerável incentivo às novas ideias, que auferiram pouco alcance, ficando restritas a pequenos grupos de intelectuais. Não obstante, no governo josefino (1750-1777) pode-se visualizar um maior alcance em termos institucionais dessas novas ideias, que afirmavam um posicionamento contrário ao seiscentismo e à Companhia de Jesus, configurando a contraposição entre luzes e trevas: de um lado os inacianos, responsáveis pelo marasmo pedagógico e isolamento intelectual português; do outro, o Estado pombalino como baluarte das luzes. ${ }^{19}$

${ }^{18}$ Ibidem, p. 34.

${ }^{19}$ Ibidem.

Revista Vernáculo n. ${ }^{\circ} 42$ - segundo semestre /2018 
Antes de darmos sequência nas especificidades da Reforma dos Estatutos, pensamos ser lícito lançar nossos olhares para esse quadro de homens ilustrados que desempenharam intensa atividade no contexto $^{20}$. Quem eram? O que produziram? Quais as suas influências?

\title{
Pensadores portugueses ilustrados
}

Uma das mais eminentes figuras do meio ilustrado português nessa época foi o clérigo teatino Rafael Bluteau. Nascido em Londres, estudou em prestigiadas instituições francesas, como o Colégio La Fléche, em Paris, e o Colégio jesuíta situado na cidade de Clermont. Antes de se mudar para Portugal, em 1668, passou ainda pelas universidades de Roma, Paris e Verona. ${ }^{21}$

\begin{abstract}
Bluteau faleceu em 1734, na cidade de Lisboa, portanto não conheceu outros tantos personagens que viriam a marcar fortemente a ilustração no Reino. Não obstante destacou-se em um contexto que prenunciava uma efervescência intelectual vindoura. Seu abastado conhecimento enciclopédico materializou-se no monumental Vocabulário Portuguez e Latino, publicado em oito volumes, no ano de 1721. Indo na esteira do movimento ensejado por D. Francisco Xavier de Menezes contribuiu em assuntos relativos à física, astronomia, notadamente o problema da duração da terra, além de promover críticas aos peripatéticos, colocando em relevo a superioridade da ciência moderna em relação à antiga.
\end{abstract}

${ }^{20}$ Sobre história intelectual ver: CHARTIER, Roger. História intelectual e história das mentalidades: uma dupla reavaliação. In: A História Cultural: entre práticas e representações. Rio de Janeiro: Bertrand Brasil, 1990.

21 SILVESTRE, João Paulo. O Vocabulário Portuguez e Latino: principais características lexicográficas da obra de Rafael Bluteau. Anais eletrônicos. Comunicação apresentada no encontro Dicionários da Língua Portuguesa Património e renovação, Cursos da Arrábida, 20 a 22 de agosto de 2001, p. 1-13. Revista Vernáculo n. ${ }^{\circ} 42$ - segundo semestre /2018 
Publicou Instrução sobre a cultura das amoreiras $e$ criação dos bichos da seda em 1769, o que comprova sua preocupação com as questões econômicas do Reino. Difundiu com não pouco entusiasmo a cultura literária francesa em Portugal, sendo que Boileau, um dos autores introduzidos em tal cenário por Bluteau, viria a ser a base da crítica estética dos Árcades para com os literatos barrocos. ${ }^{22}$

Nascido em 1693, Martinho de Mendonça de Pina e Proença dedicou-se sobretudo à difusão do pensamento pedagógico de renomados autores, tais como John Locke, Rollin e Fénelon. Autodidata, debruçou-se sobre o direito, a matemática e o grego, além da Retórica e do Latim. Ingressou no curso de Filosofia em Coimbra, mas não o concluiu. ${ }^{23}$

Em busca de novos saberes, foi aventurar-se no alémfronteiras, inscrevendo seu nome no grupo conhecido como Estrangeirado. De volta a Portugal, imbuído de um espírito renovado após contato com as ideias reluzentes, Pina e Proença dedica-se com mais afinco ao meio intelectual, desta vez participando de atividades na Academia Real de História Portuguesa, patrocinada por D. João V, e na Academia dos Anônimos. ${ }^{24}$

\section{Os Apontamentos para a educação de um menino nobre (1761)} são sua obra mais importante; construída de acordo com o modelo do

${ }^{22}$ Ibidem.

${ }^{23}$ CAVALCANTI, Irenilda Reinalda Barreto de Rangel Moreira. O comissário real Martinho de Mendonça: práticas administrativas na primeira metade do século XVIII. Universidade Federal Fluminense - Niterói: Tese de Doutorado em História Social, 2010. p. 189.

${ }^{24}$ Ibidem.

Revista Vernáculo n. ${ }^{\circ} 42$ - segundo semestre /2018 
espelho de príncipe, traduz em grande medida as proposições pedagógicas de Fénelon contidas em seu De l'éducation des filles (1688), além de Rollin (Traité des Études, 1726) e John Locke (Some Thoughts Concerning Education, 1693). ${ }^{25}$ Proença faleceu em 1743, na cidade de Lisboa.

Manuel de Azevedo Fortes nasceu em 1660, na cidade de Lisboa, local onde faleceria em 1749. Renomado engenheiro militar, destacou-se nos estudos sobre lógica. Lógica Racional, Geométrica e Analítica (1744) foi a primeira composição sobre tal matéria escrita em língua portuguesa. A temática atinente ao método foi muito cara ao iluminismo; desse modo, podemos ter clara noção da importância de que esse trabalho se revestiu naquela conjuntura. Aqui, o sensismo lockeano aparece uma vez mais, apesar do diálogo com o inatismo cartesiano, no plano da teoria das ideias. ${ }^{26}$

Fato é que o iluminismo português se confunde com a figura de Luís Antônio Verney, autor da célebre obra $O$ verdadeiro método de estudar, que veio à luz em 1746. Verney nasceu em 1718, na cidade de Lisboa, e faleceu em Roma, no ano de 1792. Iniciou seus estudos no colégio jesuíta de Santo Antão, passando pelo curso de filosofia com os oratorianos (1727-1730), e por Évora, onde bacharelou-se e licenciou-se

\section{${ }^{25}$ Ibidem.}

${ }^{26}$ RIBEIRO, Dulcylene Maria. A obra "Lógica Racional, Geométrica e Analítica" (1744) de Manoel de Azevedo Fortes (1660-1749): um estudo das possíveis contribuições para o desenvolvimento educacional lusobrasileiro. Universidade Estadual Paulista, Rio Claro: Dissertação de Mestrado em Educação Matemática, 2003, p. 38-48.

Revista Vernáculo n. ${ }^{\circ} 42$ - segundo semestre /2018 
em Artes no ano de 1731. Aos 23 anos partiu para Roma, onde teria contato com personagens-chave do iluminismo italiano, como Muratori e Genovesi, vindo a desenvolver uma intensa atividade intelectual até o fim de sua vida. ${ }^{27}$

Sua obra principal, mencionada acima, propunha uma verdadeira reforma no âmbito educacional português, fazendo-se necessário para isso repensar o paradigma educacional da Companhia de Jesus. Com tintas ácidas escreve contra a lógica peripatética, dando ênfase à importância da física newtoniana, e rechaçando a concepção cartesiana de sistema, deixando manifesto o ecletismo do qual parte sempre. $\mathrm{Na}$ esfera retórica difundiu as noções seminais do Neoclassicismo, primando pela excelência do estilo natural. ${ }^{28}$ Sobre o estado de tal matéria em Portugal, o autor brada:

E, na verdade, não há coisa mais útil que a Retórica; mas, não há alguma que com mais negligência, se trate neste Reino; se V.P. observar o que os mestres ensinam nas escolas, achará que é uma embrulhada que nenhum homem, quanto mais rapaz, pode entender. Primeiramente, ensinam a Retórica em Latim. Erro considerável, porque nada tem a Retórica com o Latim, sendo que os seus preceitos compreendem e se exercitam em todas as línguas (...). ${ }^{29}$

27 ANDRADE, Antônio Alberto de. Vernei e a cultura do seu tempo. Coimbra: Imprensa da Universidade de Coimbra, 1966, p. 9.

${ }^{28}$ CARVALHO JUNIOR, Eduardo Teixeira de. Op. cit., p. 83-105.

${ }^{29}$ VERNEI, Luís Antônio. O verdadeiro método de estudar. Lisboa: Editorial Verbo, 1965, p. 43.

Revista Vernáculo n. ${ }^{\circ} 42$ - segundo semestre /2018 
Quando trata da metafísica, assinala que a função primordial do filósofo é indagar a existência do Espírito Eterno, aquele que se configura como a causa motriz de tudo que existe. $O$ verdadeiro método foi composto à maneira epistolar, em dezesseis cartas abordando diversas matérias, e foi publicado anonimamente sob o pseudônimo de Padre Barbadinho. Verney ainda publicou outras obras sobre lógica, metafísica, física e gramática. ${ }^{30}$

Uma das trajetórias mais surpreendentes entre os personagens abordados foi a de Manuel do Cenáculo Villas Boas, figura abastada intelectualmente que nasceu em Lisboa no ano de 1724 e faleceu em Évora no ano de 1814. A longevidade de sua existência caracterizou-se por uma intensa atividade intelectual em várias esferas da sociedade lusitana de seu tempo. ${ }^{31}$

Foi superior provincial da Ordem Terceira de São Francisco, presidente da Real Mesa Censória, bispo de Beja, arcebispo de Évora etc. Com Frei Joaquim de São José teve aulas que o colocaram em contato com as novas perspectivas críticas em relação à escolástica. Doutorou-se em teologia pela Universidade de Coimbra, vindo a ser nomeado lente de Artes no colégio de São Pedro. ${ }^{32}$

${ }^{30}$ CARVALHO JUNIOR, Eduardo Teixeira de. Op. cit., p. 83-105.

31 PEREIRA, Cassiana Dias. O projeto educativo de Dom Frei Manuel do Cenáculo no contexto das reformas modernizadoras do ensino em Portugal na segunda metade do século XVIII. Universidade Estadual de Maringá, Maringá, PR: Tese de Doutorado em Educação, 2015. p. 49.

${ }^{32}$ Ibidem. 
Sua obra Conclusiones Philosophicas (1747) já traz severas críticas à filosofia escolástica dos jesuítas. Cenáculo viaja para Roma em 1750, onde amplia seu leque de conhecimentos, e retorna a Portugal com novas perspectivas, sempre em busca da harmonização entre fé e razão, no sentido de contribuir para a transformação do homem na sua vida em sociedade. ${ }^{33}$ Sua destacada atuação como pedagogo é bem conhecida no tempo em que foi Superior Provincial da Ordem Terceira, presidente da Real Mesa Censória e membro da Junta de Providência Literária. Além de ter contribuído na confecção dos principais documentos pombalinos da reforma educacional, resultaram de sua atuação na primeira instituição dois volumes de suas diversas Disposições (1776) e ainda um outro de Memórias Históricas do Ministério do Púlpito (1776), dedicando espaço para a reflexão sobre a reforma da retórica sacra. Como Bispo de Beja publicou diversas instruções, as quais objetivavam orientar seu clero no sentido de educar os jovens de acordo com as novas premissas científicas daquele tempo. ${ }^{34}$ Para mais, dedicou grande parte da vida ao patrimônio português, promovendo a fundação de museus, academias e bibliotecas. ${ }^{35}$ Seu ecletismo estava de acordo com o espírito das luzes, onde a filosofia se confundia com as demais áreas do conhecimento,

${ }^{33}$ Ibidem, p. 130.

${ }^{34}$ Ibidem, p. 49-92.

35 OLIVEIRA, Maria Carolina Ferreira de. A bibliofilia em Portugal no início da época contemporânea: o exemplo de Dom Frei Manuel do Cenáculo. v. 1. Universidade de Évora, Portugal: Tese (Doutorado em Ciências da Informação e da Documentação), 2012, p. 43-60.

Revista Vernáculo n. ${ }^{\circ} 42$ - segundo semestre $/ 2018$ 
tencionando sempre a aplicação prática do conhecimento teórico. Cenáculo não foi tão crítico à escolástica como Verney. Em lógica orientou-se por um matematismo remetente ao período renascentista. Por fim, no que se refere à retórica, valorizou o ideal do bom gosto, característico daqueles autores que criticaram a retórica barroca. ${ }^{36}$

Entre os mais destacados professores de filosofia em Portugal figura Antônio Soares Barbosa. Nascido em Ansião no ano de 1734, ganhou prestígio por conta da publicação de duas obras, quais sejam, o Discurso sobre o bom e verdadeiro gosto na Filosofia (1776) e o Tratado Elementar de Filosofia Moral (1792). Ocupou a cadeira de Lógica, Metafísica e Ética na Universidade de Coimbra, após esta ter sido reformada, e em 1791 tornou-se diretor da faculdade de Filosofia. As referidas obras não discrepam do espírito ilustrado desse tempo, pelo contrário, reforçam os pontos nodais do iluminismo que as fizeram ser compostas. ${ }^{37}$

Figura de extraordinária relevância no meio pedagógico e médico do período, Antônio Nunes Ribeiro Sanches teve influência decisiva na produção dos novos Estatutos da Universidade de Coimbra. Nascido em Penacor, no ano de 1699, e falecido em Paris, no ano de 1783, passou longos anos no exterior, o que lhe proporcionou contato com as novas ideias vigentes, disso resultando o seu afã em restaurar a cultura portuguesa. Desse autor, destacam-se Cartas sobre a educação

${ }^{36}$ PEREIRA, Cassiana Dias. Op. cit., p. 143-146.

${ }^{37}$ PEREIRA, José Antônio. O problema moral em Antônio Soares Barbosa. Estudos Filosóficos, São João del-Rei, n. 7, p. 89-105, 2011.

Revista Vernáculo n. ${ }^{\circ} 42$ - segundo semestre /2018 
da mocidade (1760) e o Método para aprender e estudar a Medicina (1763). ${ }^{38}$

$\mathrm{O}$ tom regalista dessas obras, que atenderia às exigências da política pombalina, fazia-se notar ao lado de ideias como a laicização da sociedade, a espiritualização das ações da igreja, o cosmopolitismo pedagógico, além da defesa dos principais ditames da ilustração. ${ }^{39} \mathrm{~A}$ ideia correspondente à educação em benefício do Estado é visível no trecho que segue:

A educação da mocidade não é mais que aquele hábito adquirido pela cultura e direção dos mestres, para obrar com facilidade e alegria ações úteis a si e ao Estado onde nasceu. Mas, para se cultivar o ânimo da mocidade, para adquirir a facilidade de obrar bem e com decência, não basta o bom exemplo dos pais, nem o ensino dos mestres: é necessário que no estado existam tais leis que premeiem a quem for mais bem criado, e que castiguem a quem não quer ser útil nem a si nem à sua pátria. ${ }^{40}$

Cumpre salientar o fato de que Ribeiro Sanches defendia a restrição do acesso à educação aos membros da elite, em convergência com sua base fisiocrática no que diz respeito à sua concepção econômica. ${ }^{41}$

${ }^{38}$ BOTO, Carlota. O enciclopedismo de Ribeiro Sanches: pedagogia e medicina na confecção do Estado. Revista de História da educação, Pelotas, n. 4, p. 107-117, 1998.

${ }^{39}$ Ibidem.

40 SANCHES, Antônio Nunes Ribeiro. Cartas sobre a educação da mocidade. Porto: Editorial Domingos Barreira, s/d, p. 125-126.

${ }^{41}$ BOTO, Carlota. Op. cit.

Revista Vernáculo n. ${ }^{\circ} 42$ - segundo semestre /2018

ISSN 2317-4021 
Teodoro de Almeida (1722-1804) também foi membro do quadro de intelectuais ao qual estamos nos referindo. Foi um membro da Congregação do Oratório que teve que se exilar no estrangeiro, devido à perseguição do marquês de Pombal. Autor de obras como Recreação Filosófica (1751-1799) e O Feliz Independente do Mundo e da Fortuna (1779), buscou ao longo de sua jornada harmonizar a filosofia ilustrada com os preceitos cristãos. Assim como os demais intelectuais do contexto, refletiu sobre os vários ramos do saber. ${ }^{42}$

Em uma carta enviada a um amigo de nome Emílio Lúcio Crespo, datada de 4 de julho de 1780, podemos visualizar bem o ânimo de Almeida quanto às luzes renovadoras do conhecimento em Portugal. Cabe notar que em 1779 era fundada a Academia Real das Ciências de Lisboa, cuja oração de abertura foi proferida por esse célebre padre. Vejamos as palavras de Almeida:

He pois pena que quem adornou o seu espírito com uma educação sabia e desabusada ficasse fora da sociedade daqueles homens que dizer vem a emendar os erros da nossa literatura e com a sua companhia aperfeiçoar e pulir outros para caminharem seguramente para a glória. O ceo permita que os fins correspondão a tãos bons intentos! Mas amigo do coração devo lembrar-lhe que hoje estes mestres sábios acham a nação como certamente não o julgam. Há mais de trinta anos (sem falarmos nos nossos bons e dourados séculos) se tem trabalhado nessa nação com gosto sólido e puro, com o conhecimento de muitas artes e ciências que eram ou totalmente ignoradas ou soterradas em Portugal. Temos escolas de Humanidades,

${ }^{42}$ SANTOS, Eugénio dos. Para a história da cultura em Portugal no século XVIII: Oração de abertura da Academia de Ciências de Lisboa do padre Teodoro de Almeida. Repositório Digital Universidade do Porto, 1980, p. 53-90. 
Ciências Naturais, Físicas, Matemáticas, aonde se educaram moços que deram crédito a Portugal. O direito se aprendeu depuradamente sem sutilezas, nem sofismas. Enfim leia-se com os olhos dezempoados de paixão o plano da nova fundação da Universidade de Coimbra e então se verá como as ciências e gosto crescia ao olho. Clamem muito embora desentoadamente ou os partidistas da ignorância que ainda querem revocar os seus antigos e medonhos; ou outros que tapam os olhos por não verem as preciosidades do seu país, gabando em extremo tudo o que lhe alhejo, ou outros que ainda o contam entre as nações bárbaras e selvagens. ${ }^{43}$

Devemos ainda destacar como figuras cimeiras das luzes portuguesas homens como: Antônio Pereira de Figueiredo (1725-1797), autor do Novo Methodo da Grammatica Latina (1753) e dos Elementos de Invenção e Locuçam Retorica ou Princípios da Eloquência (1759); Jacob de Castro Sarmento (1691- 1762), autor da Theorica Verdadeira das Marés conforme à Philosophia do incomparável cavalheiro Isaac Newton (Londres, 1737); Bento de Souza Farinha (1740-1820), cujo trabalho de difusor das obras pedagógicas mais relevantes ao seu entender sobressaiu ao seu lado autoral; e Francisco José Freire (17191773), do qual falaremos mais à frente. ${ }^{44}$

"Que lhe direi da famosa Arcádia em que uns poucos de homens que por curiosidade se ajuntaram e a dispuseram de maneira que cresceu com tão arraigadas raízes que brotou copioso fruto da boa literatura”. ${ }^{45}$ Que boa literatura era essa à qual Teodoro de Almeida se

${ }^{43}$ Ibidem, p. 80.

${ }^{44}$ TUNA, Gustavo Henrique. Op. cit., p. 14-25.

${ }^{45}$ SANTOS, Eugênio dos. Op. cit.

Revista Vernáculo n. ${ }^{\circ} 42$ - segundo semestre /2018

ISSN 2317-4021 
referia na já comentada carta? Quais suas características? Seus personagens? O que a Arcádia representou para o período em questão?

\section{Literatura e Ilustração em Portugal}

De um modo geral, a literatura setecentista realizou-se sob a tríade "razão, natureza e verdade". Arcadismo, Neoclassicismo e Ilustração conformaram o quadro de manifestações artísticas do século XVIII. Os espanhóis e os ingleses acreditavam que o Neoclassicismo era imitação do Classicismo francês, presente em toda a Europa no período. O Arcadismo é oriundo da Arcádia Lusitana de 1756, e teve fortes influências italianas. Segundo Antônio Cândido, a literatura feita nessa conjuntura pode ser resumida no seguinte postulado: “O verdadeiro é o natural, o natural é o racional". ${ }^{46}$

O Arcadismo português fora pungente em sua crítica. A poesia marcou a reconquista do ordinário à prosa, pintando o período com cores clássicas. Em Portugal a renovação cultural de grandes dimensões que ocorreu nesse tempo englobou tal movimento. Como aventado anteriormente, Luís Antônio Verney desempenhou um importante papel nessa renovação. Em seu ponto de vista, o objetivo da arte seria a verdade, e o domínio da Retórica, a lógica essencial para o bom poeta. ${ }^{47}$

A ideia de "utilidade", cara ao pensamento ilustrado, fez-se notar na perspectiva de Francisco José Freire (Cândido Lusitano),

${ }^{46}$ CANDIDO, Antônio. A formação da literatura brasileira: momentos decisivos. 6. ed. Belo horizonte: Itatiaia, 2000, p. 42.

${ }^{47}$ Ibidem, p. 45-46.

Revista Vernáculo n. ${ }^{\circ} 42$ - segundo semestre $/ 2018$ 
fundador da Arcádia Lusitana (1756). O poeta acreditava que sua arte tinha serventia moral, devendo instruir e deleitar o leitor. ${ }^{48}$ Nas palavras do autor, "Não pode entrar em dúvida, que o principal fim da poesia não seja o ensinar o povo, e servir-lhe de utilidade." 49 E no que toca ao deleite

Pode-se dizer, que a poesia, ou a poética, enquanto é arte imitadora, e compositora de poemas, tem por fim o deleitar, e que enquanto é arte subordinada à filosofia moral, ou à política, têm por fim o utilizar alguém. Com esta doutrina, que é do ilustre Muratori, se vê que a mesma coisa considerada de diferente maneira, têm dois fins diversos, isto é, a utilidade e o deleite. A poesia considerada em si mesma procura causar seu deleite, e considerada como arte sujeita à faculdade civil toda fé emprega em causar utilidade. E como quer que esta faculdade seja a mesma que encaminha todas as ciências e artes à felicidade eterna, à temporal, e ao bom governo dos povos, por isso a verdadeira, e perfeita poesia, deveria sempre igualmente deleitar, que utilizar a uma república. ${ }^{50}$

Sua obra contribuiu demasiadamente no sentido de superação do intelectualismo fantasioso. Fato é que autores como Cândido Lusitano tencionavam transformar a literatura em meio de comunicação entre os homens, no sentido de criar uma consciência integradora. A

${ }^{48}$ Ibidem, p. 46.

${ }^{49}$ FREIRE, Francisco José. Arte Poética, ou regras da verdadeira poesia, e de todas as suas espécies principais, tratadas com juízo crítico. Tomo I. Lisboa, Oficina patriarcal F. Luís Ameno, 1748, p. 26.

${ }^{50}$ Ibidem, p. 29.

Revista Vernáculo n. ${ }^{\circ} 42$ - segundo semestre /2018

ISSN 2317-4021 
noção de "cópia do real", característica dessa poesia, remete à mimesis aristotélica, tão importante para esses poetas quanto a obra horaciana. ${ }^{51}$

No século XVIII, a ideia de "razão" não estava mais ancorada nas elucubrações cartesianas. Pensadores como Newton, Buffon e Lineu apontaram uma lei geral, a qual era obedecida pela atividade do espírito. Tal lei seria a razão unificadora, em outras palavras, a própria razão universal. Nesse sentido, a ideia de "natureza" ganha enorme destaque, assim como o preceito horaciano de "sinceridade" e ainda o "homem natural", refletindo o momento ideológico da conjuntura. Cabe notar que a noção de "naturalidade" implicou na "espontaneidade", abrindo margem para o Sentimentalismo. Daí a dicotomia entre razão do coração e razão lógica, assinalando o limiar do Romantismo. Malgrado a permanência da razão lógica em Portugal e na América portuguesa setecentista, vemos aspectos de poesia romântica em Glaura, de Manuel Inácio da Silva Alvarenga. ${ }^{52}$

Boileau, figura central para a compreensão literária em pauta, assinalou que razão, verdade e natureza seriam uma coisa só. O Classicismo francês do século XVIII tinha fortes entonações sociais. A verdade estava associada à relação do homem com o seu semelhante, denotando a preocupação com a justiça social. Todo esse quadro recebeu influxo dos grandes pensadores das lumières, como Rousseau, Montesquieu e os enciclopedistas. ${ }^{53}$

${ }^{51}$ CÂNDIDO, Antônio. Op. cit., p. 46.

${ }^{52}$ Ibidem, p. 53-55.

${ }^{53}$ Ibidem, p. 56.

Revista Vernáculo n. ${ }^{\circ} 42$ - segundo semestre /2018 
A Arcádia portuguesa caracterizou-se pelos gêneros pastorais, como o Bucolismo, sendo a natureza objeto de grande destaque, e pela visível transferência do "eu" para a figura do pastor. Destaca-se na América portuguesa a vertente indianista, que intentou mediar a valorização da rusticidade com os cânones europeus. ${ }^{54}$

No ultramar, as Obras poéticas (1756) de Cláudio Manuel da Costa são o marco inicial do Arcadismo, que teve entre seus representantes Tomás Antônio Gonzaga, Alvarenga Peixoto, José Basílio da Gama, Frei José de Santa Rita Durão e Manuel Inácio da Silva Alvarenga. ${ }^{55}$

\section{Os Novos Estatutos}

Em uma carta de 23 de dezembro de 1770, D. José I atentou para a necessidade da criação de uma junta de providência literária, voltada para o levantamento das causas da decadência e ruína do ensino universitário. Esta funcionou sob a inspeção do cardeal dom João Cosme da Cunha (presidente) e de Pombal, compondo-se de sete membros: Frei Manuel do Cenáculo; José Ricale Pereira de Castro; José de Seabra da Silva; Francisco Antônio Giraldes; Francisco de Lemos; Manuel Pereira da Silva e João Pereira Ramos de Azevedo Coutinho. ${ }^{56}$ Em 28 de agosto de 1771 a junta apresentou a D. José o Compêndio Histórico do estado da Universidade de Coimbra, que

${ }^{54}$ Ibidem.

${ }^{55}$ Ibidem.

${ }^{56}$ CARVALHO, Flávio Rey de. Op. cit., p. 35.

Revista Vernáculo n. ${ }^{\circ} 42$ - segundo semestre /2018 
foi organizado em três partes: a primeira, dividida em quatro prelúdios, relatou, de maneira histórica e cronológica, os danos cometidos às leis, às regras e aos métodos que regiam a Universidade; a segunda apresentou, em três capítulos, os danos cometidos à Teologia, às jurisprudências canônica e civil e à medicina; a terceira consistiu em um apêndice ao segundo capítulo da segunda parte, sobre Moral e Ética. ${ }^{57}$

Os jesuítas haviam composto quatro estatutos para Coimbra antes de 1772: nos anos de 1565, 1592, 1598 e 1612. A ausência de reflexão sobre o método era uma falta grave, apontada em tintas ácidas pelos autores do documento. Perpassam o Compêndio críticas atinentes à preponderância da filosofia arábico-aristotélica, o menoscabo para com o estudo das línguas grega e latina, a ausência de matérias propedêuticas em relação a diversas disciplinas, a desorganização do saber ensinado nas cadeiras universitárias e a privação do Ecletismo no campo geral do conhecimento. Para mais, a reprimenda era direcionada ao fato de não haver por parte dos execrados religiosos o devido manejo das fontes primárias, além do baixo nível da instrução oferecida nas escolas menores e, por fim, a desarmonia entre as três faculdades que compunham a Universidade de Coimbra. ${ }^{58}$

Os autores observaram que o conhecimento jesuíta era transmitido de forma a moldar as mentes dos alunos, aonde o filtro interpretativo de cada professor resultava em um saber adaptado, parcial e descontextualizado, tornando os jovens meros repetidores. Nesse

${ }^{57}$ Ibidem, p. 36.

${ }^{58}$ Ibidem, p. 37.

Revista Vernáculo n. ${ }^{\circ} 42$ - segundo semestre /2018 
ínterim, o ecletismo seria importante para evitar-se o privilégio a um modo de pensar apenas. Tal premissa foi fortemente defendida por Diderot também. ${ }^{59}$

Em 25 de setembro de 1771 os estatutos dos inacianos foram suspensos e 11 meses depois, no dia 28 de agosto de 1772, publicou-se a carta régia de confirmação do novo regimento de Coimbra. Comentaremos brevemente acerca da Reforma da Faculdade de Leis e da criação da Faculdade de Filosofia.

Confeccionados na esteira do Compêndio Histórico, os novos Estatutos foram divididos em três volumes, centrando-se em dois aspectos fundamentais: "as disposições relativas à administração (a idade mínima para o ingresso na Universidade, determinação sobre a realização das matrículas, a duração dos cursos, a prescrição dos feriados, dentre outras) e as atinentes às questões pedagógicometodológicas da instituição". ${ }^{60}$

O século XVIII, no âmbito jurídico, foi marcado pela racionalização e pela crítica universal, de modo que

A reforma da faculdade de Leis, envolvida pelo espírito jurídico ilustrado da República das Letras, consagrou-se: pela implementação de uma grade curricular fixa e ordenada, com conexões claras entre os conteúdos e as funções dos saberes teóricos e a sua prática na aplicação jurisprudencial; pelo esforço, sob o regalismo josefino à delimitação das esferas de atuação jurídica dos direitos canônico e civil; pela valorização do ensino de interpretação e aplicação das leis pátrias; pela adoção da

${ }^{59}$ Ibidem, p. 46-47.

${ }^{60}$ Ibidem, p. 52.

Revista Vernáculo n. ${ }^{\circ} 42$ - segundo semestre /2018

ISSN 2317-4021 
Escola cujaciana, que destacava o estudo da jurisprudência, embasado em pesquisas históricofilológicas; pela adoção do método sintéticodemonstrativo-compendiário em estudos propedêuticos às lições analíticas; pela criação da cadeira de Direito Natural; pelo uso da boa razão como fonte e parâmetro de validação do direito e pela utilização subsidiária das leis romanas para os casos omissos, desde que presentes nas nações modernas europeias e, simultaneamente, estando em conformidade com a boa razão. $O$ conjunto desses elementos, concatenados entre si, voltava-se à instrução de bacharéis, em leis, habilitados para o emprego prático dos ditames apregoados pelo decreto de 18 de agosto de 1769, que - na linha do pensamento dos filósofos franceses, Voltaire e Montesquieu - objetivava cercear a antiga prática jurisprudencial doutrinária e interpretativa dos juízes, em prol do cumprimento claro, uniforme e preciso das leis. ${ }^{61}$

Antes da criação da Faculdade de Filosofia na Universidade de Coimbra, o ensino de tal matéria circunscrevia-se ao âmbito das Escolas Menores, sob a tutela dos jesuítas, que ministravam aulas de Matemática, Metafísica, Ética e Moral, sempre vinculadas à Teologia. Com a Reforma de 1772 houve uma ampliação da matéria filosófica implantada nos ramos da Matemática, Medicina e Filosofia natural. ${ }^{62}$

A partir desse regimento, quem fosse se aventurar nos estudos filosóficos teria quatro anos pela frente, tendo que estudar Filosofia Racional no primeiro ano do curso (Lógica, Metafísica e Ontologia) e também Filosofia Moral (Ética). No segundo ano, haveria lições de História Natural. Antes de estudar Física Experimental no terceiro ano,

${ }^{61}$ Ibidem, p. 92.

${ }^{62}$ CARVALHO, Flávio Rey de. Op. cit., p. 96.

Revista Vernáculo n. ${ }^{\circ} 42$ - segundo semestre /2018

ISSN 2317-4021 
seria necessário aprender Geometria e Matemática como disciplinas propedêuticas. E por fim, no quarto ano haveria aulas de Química. ${ }^{63}$

O entendimento filosófico presente nos Estatutos de 1772 converge com o novo ideário advindo das Luzes. A nova concepção de filosofia, que abrangia amplo quadro de matérias, foi pensada em Portugal em concatenação com as necessidades político-econômicas da coroa. A crise nos rendimentos coloniais forçou o governo português a elaborar uma estratégia política para contornar tal situação. Sob a égide do Marquês de Pombal, não só a Filosofia Natural como a nova forma de pensar o Direito estiveram a serviço dos desígnios reais. O incentivo à pesquisa filosófica tencionava o conhecimento e, portanto, o aproveitamento das potencialidades coloniais.

\section{Apreciações finais}

O presente trabalho buscou olhar o fenômeno iluminista português por meio de sua produção intelectual. Desse modo, procuramos entender como o pensamento em Portugal no setecentos se configurou. Vimos que o ápice das luzes no Reino se deu sob a égide de Sebastião José Carvalho e Melo, o Marquês de Pombal, primeiro ministro de D. José I, que cercou-se dos intelectuais mais importantes

${ }^{63}$ Ibidem, p. 102-103.

Revista Vernáculo n. ${ }^{\circ} 42$ - segundo semestre /2018 
no intuito de promover uma política reformista que, como anotamos, privilegiou a educação.

O iluminismo em Portugal pode ser entendido como uma atualização da tradição. Como dito anteriormente, os primeiros ventos renovadores sopraram no tempo em que D. João V reinara, atestando isso a publicação de $O$ verdadeiro método de estudar, do intelectual Luís Antônio Verney, em 1746. Assim como outras obras, essa exerceu grande influxo nas ações reformadoras de Pombal. A Companhia de Jesus foi fortemente rechaçada no que tange ao seu sistema pedagógico. Se sob o governo joanino não houve um posicionamento diretamente afirmado contra os inacianos, os documentos reais que embasaram a reforma da Universidade de Coimbra em 1772 inscreveram definitivamente tal postura.

Nesse seguimento, localizamos os pontos seminais da produção literária portuguesa que convergiu com o novo ideário e contribuiu para a participação de Portugal no contexto dos vários iluminismos europeus. Podemos visualizar ainda que o pedagogismo idiossincrático da ilustração foi refletido em terras lusitanas por meio do ecletismo exercido pelos homens de letras, seja pelos filósofos ou pelos literatos.

\section{Referências:}

ANDRADE, Antônio Alberto de. Vernei e a cultura do seu tempo. Coimbra: Imprensa da Universidade de Coimbra, 1966. 
BIRON, Berty. Considerações acerca do iluminismo luso-brasileiro. RCL, Convergência Lusíada, n. 32, jul. / dez. 2014.

BOTO, Carlota. O enciclopedismo de Ribeiro Sanches: pedagogia e medicina na confecção do Estado. Revista de História da educação, Pelotas, n. 4, p. 107-117, 1998.

CANDIDO, Antônio. A formação da literatura brasileira: momentos decisivos. 6. ed. Belo Horizonte: Itatiaia, 2000.

CARDOSO, Tereza Maria Rolo Fachada Levy. As luzes da educação: fundamentos, raízes históricas e prática das aulas régias no Rio de Janeiro. 1759-1834. Bragança Paulista: Editora da Universidade São Francisco, 2002.

CARVALHO, Flávio Rey de. Um Iluminismo português? A Reforma da Universidade de Coimbra de 1772. Universidade de Brasília: Dissertação de Mestrado, 2007.

CARVALHO JÚNIOR, Eduardo Teixeira de. O método em Verney e o Iluminismo em Portugal. Universidade Federal do Paraná, Curitiba: Tese de Doutorado em História, 2015.

CAVALCANTI, Irenilda Reinalda Barreto de Rangel Moreira. O comissário real Martinho de Mendonça: práticas administrativas na primeira metade do século XVIII. Universidade Federal Fluminense Niterói: Tese de Doutorado em História Social, 2010.

CHARTIER, Roger. História intelectual e história das mentalidades: uma dupla reavaliação. In: A História Cultural: entre práticas e representações. Rio de Janeiro: Bertrand Brasil, 1990.

COSTA, Mário Júlio de Almeida; MARCOS, Rui de Figueiredo. Reforma Pombalina dos estudos jurídicos. In: O Marquês de Pombal e a Universidade. 2. ed. Coimbra: Imprensa da Universidade, 2014. p. 97-125.

FREIRE, Francisco José. Arte Poética, ou regras da verdadeira poesia, e de todas as suas espécies principais, tratadas com juízo crítico. Tomo I. Lisboa: Oficina patriarcal F. Luís Ameno, 1748. 
OLIVEIRA, Maria Carolina Ferreira de. A bibliofilia em Portugal no início da época contemporânea: o exemplo de Dom Frei Manuel do Cenáculo. v. 1. Universidade de Évora, Portugal: Tese (Doutorado em Ciências da Informação e da Documentação), 2012.

PEREIRA, Cassiana Dias. O projeto educativo de Dom Frei Manuel do Cenáculo no contexto das reformas modernizadoras do ensino em Portugal na segunda metade do século XVIII. Universidade Estadual de Maringá, Maringá, PR: Tese de Doutorado em Educação, 2015.

PEREIRA, José Antônio. O problema moral em Antônio Soares Barbosa. Estudos Filosóficos, São João del-Rei, n. 7, p. 89-105, 2011.

RIBEIRO, Dulcylene Maria. A obra "Lógica Racional, Geométrica e Analítica" (1744) de Manoel de Azevedo Fortes (1660-1749): um estudo das possíveis contribuições para o desenvolvimento educacional lusobrasileiro. Universidade Estadual Paulista, Rio Claro: Dissertação de Mestrado em Educação Matemática, 2003.

SANCHES, Antônio Nunes Ribeiro. Cartas sobre a educação da mocidade. Porto: Editorial Domingos Barreira, s/d.

SANTOS, Cândido dos. Matrizes do Iluminismo católico da época pombalina. Faculdade de Letras da Universidade do Porto, 2004, p. 949-956.

SANTOS, Eugénio dos. Para a história da cultura em Portugal no século XVIII: Oração de abertura da Academia de Ciências de Lisboa do padre Teodoro de Almeida. Repositório Digital Universidade do Porto, 1980, p. 53-90.

SILVESTRE, João Paulo. O Vocabulário Portuguez e Latino: principais características lexicográficas da obra de Rafael Bluteau. Anais eletrônicos. Comunicação apresentada no encontro Dicionários da Língua Portuguesa - Património e renovação, Cursos da Arrábida, 20 a 22 de agosto de 2001, p. 1-13.

TEIXEIRA, Ivan. Mecenato pombalino e a poesia neoclássica. São Paulo: Edusp, 1999. 
TUNA, Gustavo Henrique. Silva Alvarenga: representante das luzes na América portuguesa. Faculdade de Filosofia, Letras e Ciências Humanas, Universidade de São Paulo, São Paulo: Tese de Doutorado em História Social, 2009.

VERNEI, Luís Antônio. O verdadeiro método de estudar. Lisboa: Editorial Verbo, 1965.

Recebido em 15/04/2018, aceito para publicação em 31/05/2018 